\title{
EFFECT OF WIND VELOCITY ON FLAME SPREAD IN MICROGRAVITY
}

\author{
Kuldeep Prasad ${ }^{1}$, Sandra L. Olson ${ }^{2}$, Yuji Nakamura ${ }^{3}$, Osamu Fujita ${ }^{4}$, \\ Katsuhiro Nishizawa ${ }^{4}$, Kenichi Ito ${ }^{4}$ and Takashi Kashiwagi ${ }^{1}$ \\ ${ }^{1}$ Building and Fire Research Laboratory \\ National Institute of Standards and Technology \\ Gaithersburg, MD 20899, USA \\ ${ }^{2}$ Microgravity Combustion Science Branch \\ NASA Glenn Research Center \\ Cleveland, OH 44135, USA \\ ${ }^{3}$ Department of Mechanical Engineering \\ Nagoya University, Nagoya, Japan \\ ${ }^{4}$ Department of Mechanical Engineering \\ Hokkaido University, Sapporo, Japan \\ $29^{\text {th }}$ Symposium (International) on Combustion \\ The Combustion Institute \\ Colloquia: Microgravity Combustion \\ Keywords : Ignition, Flame Spread \\ Word Count \\ Fig. $1-4: 800$ (1 page), Fig. $5: 400$, Fig. $6: 400$, \\ Text : 4001, Figures : 1600, \\ Total Word Count : 5601
}

Corresponding Author:

Kuldeep Prasad

National Institute of Standards and Technology

100 Bureau Drive, Stop 8663

Gaithersburg, MD 20899, USA

E-mail : kuldeep.prasad@nist.gov

Phone : (301)-975-3968

Fax : (301)-975-4052

his report is a preprint of an article submitted to journal for publication. Because of changes that lay be made before formal publication, this reprint is made available with the understanding reprint is mill not be cited or reproduced without the lat it will not be cited or 


\author{
EFFECT OF WIND VELOCITY ON FLAME SPREAD IN MICROGRAVITY \\ Kuldeep Prasad, Sandra L. Olson, Yuji Nakamura, Osamu Fujita, Katsuhiro \\ Nishizawa, Kenichi Ito and Takashi Kashiwagi
}

\begin{abstract}
A three-dimensional, time-dependent model is developed describing ignition and subsequent transition to flame spread over a thermally thin cellulosic sheet heated by external radiation in a microgravity environment. A low Mach number approximation to the Navier Stokes equations with global reaction rate equations describing combustion in the gas phase and the condensed phase is numerically solved. The effects of a slow external wind $(1-20 \mathrm{~cm} / \mathrm{s})$ on flame transition are studied in an atmosphere of $35 \%$ oxygen concentration. The ignition is initiated at the center part of the sample by generating a line-shape flame along the width of the sample. The calculated results are compared with data obtained in the 10 s drop tower. Numerical results exhibit flame quenching at a wind speed of $1.0 \mathrm{~cm} / \mathrm{s}$, two localized flames propagating upstream along the sample edges at $1.5 \mathrm{~cm} / \mathrm{s}$, a single line-shape flame front at $5.0 \mathrm{~cm} / \mathrm{s}$, three flames structure observed at $10.0 \mathrm{~cm} / \mathrm{s}$ (consisting of a single line-shape flame propagating upstream and two localized flames propagating downstream along sample edges) and followed by two line-shape flames (one propagating upstream and another propagating downstream) at $20.0 \mathrm{~cm} / \mathrm{s}$. These observations qualitatively compare with experimental data. Three-dimensional visualization of the observed flame complex, fuel concentration contours, oxygen and reaction rate isosurfaces, convective and diffusive mass flux are used to obtain a detailed understanding of the controlling mechanism. Physical arguments based on lateral diffusive flux of oxygen, fuel depletion, oxygen shadow of the flame and heat release rate are constructed to explain the various observed flame shapes.
\end{abstract}




\section{Introduction}

Ignition of solid fuels by external thermal radiation and subsequent transition to flame spread is of considerable scientific interest and will improve our understanding of the physics relevant to fire safety in spacecraft. For this reason, a number of theoretical and experimental studies [1-4] have investigated flame spread over thermally thin cellulosic materials with external flows in a microgravity environment. Many researchers [1-4] have observed the flame spread behavior in a two-dimensional configuration with a line-shape flame across the sample width and compared this with calculations based on two-dimensional models. Because of the inherent 2-D nature of the models, several important physical phenomena could not be captured. The available test chamber volume for microgravity combustion experiments is limited and the flame spread experiments are restricted to narrow samples held in place by inert sample holders, which implies that the three-dimensional flow field is important and cannot be approximated (under certain conditions) by a 2-D analysis [5,6]. Furthermore, flame spread rate along sample edges [7] depends on properties of the sample holder [5] and the distance to the chamber wall. Thus, limiting flame spread studies to the center of the sample in the intended 2-D configuration, may underestimate spread rate and quenching limits $[5,6]$.

The focus of this paper is to determine the effects of a slow imposed flow on flame spread behavior over a finite width cellulosic sample in microgravity and to understand the controlling mechanism. A 3-D mathematical model has been constructed to investigate ignition by external radiation to initiate a line shape flame, and subsequent flame spread in a confined test chamber. Results are presented for various imposed flow velocities. Simulations indicate formation of one, two, or three flames depending on the imposed wind velocity. These flame structures have not been observed earlier using 2-D computational models. Three-dimensional, time dependent visualization of the flow field velocity vectors, isosurface plots and slice contours are used to understand the controlling mechanism, to physically explain the observed flame spread patterns and to compare and contrast these results with experimental observations.

\section{Theoretical Model}

Thermally thin cellulosic paper is used as a solid fuel (140 mm long and $75 \mathrm{~mm}$ wide with an area density of $60 \mathrm{~g} / \mathrm{m}^{2}$ ) and is held in place by a carbon steel sample holder in a test chamber simulating the experimental configuration. The distance between the sample edge and 
the chamber wall is $42.5 \mathrm{~mm}$, to avoid heat loss from flame to chamber wall. The sample is ignited at the center part of the sample by an external radiant flux across its width to initially generate a line-shape flame in zero gravity. The incident radiant flux distribution is approximated as Gaussian with a peak of $70 \mathrm{~kW} / \mathrm{m}^{2}$ and a half-width of $0.25 \mathrm{~cm}$. The flux increases linearly with time, reaches its peak value at $0.75 \mathrm{~s}$, and then remains constant for $3.5 \mathrm{~s}$ from the onset of radiation. A complete description of the theoretical model for studying the flame spread on thin cellulosic sheets has been given in Refs. [3,5] and therefore, only a brief description is given here. Three exothermic degradation reactions are assumed for the pyrolysis of cellulose, thermal oxidation and char oxidation with reaction parameters identical to those in past studies [8]. Thermal conduction in the plane of the sample and heat loss to the sample holder is taken into account. Since the imposed flow velocity is very low (up to $20 \mathrm{~cm} / \mathrm{s}$ ), the low Mach number approximation and the perfect gas law assumption are applied. The gas phase is governed by three-dimensional, unsteady, conservation equations for mass, energy and species (fuel gas and oxygen). Combustion of fuel gas is described using a global, finite rate, one-step reaction (fuel gas) $+\mathrm{v}_{\mathrm{O} 2}$ (oxygen) $\rightarrow$ (products) characterized by an Arrhenius rate dependence on temperature[8]. The numerical values of the pre-exponential factor and the activation energy were determined in 1991 and have been fixed at that value in all of our calculations. With these constants, the code predicts ignition but no subsequent flame growth in $21 \%$ oxygen concentration. Note, that the objective of this study is not necessarily to duplicate experimental results by manipulating model parameters, but rather to deduce trends of the transient phenomena. Temperature dependent transport properties are estimated from kinetic theory. Radiative heat loss from the sample (constant emissivity $=0.6$ ) is included in the analysis.

The governing equations were solved using finite difference techniques on a threedimensional computational mesh. There are two planes of symmetry in the three-dimensional simulations. One parallel to the plane of the sample and passing through its middle; the other perpendicular to the plane of the sample, passing through the centerline of the sample in a direction parallel to the ambient wind. Thus, in the three-dimensional calculations, one-quarter of a corresponding experimental volume was simulated. The physical dimensions of the computational domain were $140 \times 80 \times 60 \mathrm{~mm}$ in the $\mathrm{x}, \mathrm{y}$ and $\mathrm{z}$ directions, respectively. A nonuniform rectilinear mesh containing 580,000 cells (145 X 100 X 40) was selected to resolve the flow field and ensure grid independence of the results. The mesh was stretched in the $\mathrm{x}$ and $\mathrm{z}$ directions and was uniform along the y direction (width of the sample). Gas phase variables are 
updated in time by an explicit, second order accurate predictor-corrector scheme. Those of the solid phase are updated by a first order, explicit Euler method. Divergence condition is enforced, by solving an elliptic equation for pressure using a direct Poisson solver. Typical simulations of flame spread required $16 \mathrm{CPU}$ hours per second of simulated time on the SGI Onyx $3000^{1}$ with R14000 CPUs.

The selection of appropriate flow field boundary conditions at the inlet is a difficult task. The addition of heat and mass, from ignition and flame growth, generates an expansion field that modifies the inlet and outlet flow [3,5]. In the experiments, the sample holder is placed in a tunnel like chamber and a small fan is used at the outlet to generate a specified flow condition. The fan was calibrated without any addition of heat and mass to the flow field and has not been calibrated in microgravity conditions. In the present study, it is assumed that all the expansion flow affects the upstream boundary and the outlet flow condition is fixed (the velocity profile at the downstream boundary can vary, but the average velocity is kept constant). It has been demonstrated, that the qualitative trend of flame spread does not change when either out-flow fixed or in-flow fixed boundary condition is used [9]. At the enclosure wall, a no slip condition is imposed, the wall temperature is fixed at room temperature and the normal gradient of the species concentration is set to zero. At the inlet boundary, temperature and species concentrations are ambient quantities, while zero gradient conditions are imposed at the outlet boundary.

\section{EXPERIMENT HARDWARE}

A series of experiments were conducted in the $10 \mathrm{~s}$ Japan Microgravity Center (JAMIC) facility. The experimental rig consisted of a large rectangular chamber filled with a test gas. A $12 \mathrm{~cm}$ tall by $16 \mathrm{~cm}$ wide by $18 \mathrm{~cm}$ long flow duct is mounted inside the chamber with a fan to draw the gas mixture through the test section. Sample cards mount in the center of the flow duct, to provide a uniform flow on both sides of the sample. The sample cards provide an opening for a $7.5 \mathrm{~cm}$ wide by $14 \mathrm{~cm}$ long fuel sample. Fuel samples consisting of 50\% long fibers from lumi pine and $50 \%$ short fibers from birch were made with an area density of $60 \mathrm{~g} / \mathrm{m}^{2}$. A hot wire was used to ignite the sample across the $7.5 \mathrm{~cm}$ width in the center of the sample. Ignition occurred within 3 seconds, after

\footnotetext{
${ }^{1}$ Certain commercial equipment identified in this paper in order to adequately specify the numerically procedure. Such identification does not imply recommendation or endorsement by NIST or NASA, nor does it mean that the equipment identified is necessarily the best available for the purpose.
} 
which the igniter was deactivated. A color video of the surface view was recorded, and color images of the edge view were recorded using $35 \mathrm{~mm}$ film at $2 \mathrm{~Hz}$.

\section{Results and Discussion}

Shortly after the imposition of external radiation, a half-cylindrical flame across the sample width develops over the irradiated sample area. This cylindrical flame has two flame fronts, one propagating upstream and the other downstream. When the imposed flow velocity is approximately less than $1.0 \mathrm{~cm} / \mathrm{s}$ and the atmosphere has $35 \%$ oxygen, the convective supply of oxygen is small. In this diffusion dominated regime, the amount of oxygen reaching the reaction zone is not enough to sustain the upstream flame. The oxygen supply to the downstream flame is even more restrictive, and so both flames are quickly quenched.

Fig. 1 shows results of a numerical simulation at 3,5 and $13 \mathrm{~s}$ after the onset of external radiation, when the wind velocity is increased to $1.5 \mathrm{~cm} / \mathrm{s}$. All figures in Fig. 1 show a tan colored isosurface of energy release rate value of $4000 \mathrm{Watt} / \mathrm{m}^{3}$ simulating the flame contour (gas phase reaction rate of $0.114 \mathrm{~kg} / \mathrm{m}^{3} / \mathrm{s}$ ) and blue isosurface for oxygen mass fraction value of 0.05. The sample edge, right and left clamp edge (solid lines) along with an overlaid grid (dotted line) is also shown. Since the flow field is symmetric across the $y=0$ plane, the energy release rate isosurface is shown in the $y>0$ domain, whereas the oxygen isosurface is shown in the $y<0$ domain. In order to visualize the 3-D details of the flame structure, energy release rate contours (color shaded), fuel mass fraction contours (lines) and oxygen mass flux vectors representing the convective and diffusive component have also been shown. (See Fig. 1 caption for more details).

When the imposed gas velocity is $1.5 \mathrm{~cm} / \mathrm{s}$, numerical results exhibit two localized flames propagating upstream along the sample edge (Fig. 1c). The downstream flame and the central part of the upstream flame are quenched, resulting in a flame on either side of the plane of symmetry. This bean shaped flame has larger intensity on its leading edge, and is slightly biased towards the sample edge rather than the center plane. The top view shows that the flame is hollow in the center. The question at this stage is why did the flame not quench like the $1.0 \mathrm{~cm} / \mathrm{s}$ case. Close to the sample edge, oxygen mass flux vectors (Fig. 1a) indicate lateral diffusion of oxygen from the outer flow to the flame. This lateral diffusion is not possible for flame located close to the center plane. The edge flame in Fig. 1a shows an energy release rate about three 
times larger than the center flame (top view). The fuel contours indicate the presence of fuel in the central part of the downstream flame, indicating heating from the external radiation source and the flame. As time progresses $(t=5 \mathrm{~s})$, Fig. 1b shows that the downstream edge flame and central portion of the upstream flame are also quenched. The lack of convective supply of oxygen to the reaction zone quenches the central portion of the upstream flame. Oxygen is supplied to the downstream edge flame through lateral diffusion, but is not sufficient to sustain this flame. The upstream edge flame obstructs the incoming flow and pushes the streamlines (not shown) towards the upper and side enclosure walls. Once the central flame is quenched, oxygen can diffuse from the central plane towards the flame. The expanding hot gases in the two flames obstruct the flow of oxygen and accelerate the flow in the region around the central plane. The final shape of the flame depends on the relative lateral diffusion of oxygen at the flame edge, heat loss to the sample holder and the convective flow fields. It should be noted that 2-D simulations of flame spread for a $1.5 \mathrm{~cm} / \mathrm{s}$ imposed wind speed results in immediate quenching of the flame.

Fig. 2 shows simulation results at 2, 4 and $6 \mathrm{~s}$ after the onset of external radiation when the wind velocity is set to $5 \mathrm{~cm} / \mathrm{s}$. The slice plane locations and isosurface values used for Fig. 2 are the same as for Fig. 1. Results illustrate the formation of a single flame propagating upstream (Fig. 2c). The central part of the downstream flame quenches very quickly because of the oxygen shadow (oxygen isosurface) cast by the upstream flame (Fig. 2a). The downstream edge flame survives until 4 seconds (Fig. 2b) and is subsequently quenched (Fig. 2c). Initially the oxygen shadow extends vertically upwards (Fig. 2a), due to the expansion of the hot gases. This expansion is more prominent at the center plane than the edges because of edge effects. Fig. $2 \mathrm{c}$ shows that the oxygen shadow cast by the upstream flame extends over the location of the downstream flame. As the flow velocity increases from $1.5 \mathrm{~cm} / \mathrm{s}$ to $5 \mathrm{~cm} / \mathrm{s}$ the flame becomes longer (side view of reaction rate) and the convective supply of oxygen to the upstream flame increases (See velocity vectors in Fig. 2c). As a result the central part of the upstream flame continues to propagate $(5 \mathrm{~cm} / \mathrm{s}$ case $)$ as opposed to being quenched $(1.5 \mathrm{~cm} / \mathrm{s} \mathrm{case})$. The spread rate of the upstream edge flame is greater than the center flame. This was particularly so at low imposed velocities of $2.5 \mathrm{~cm} / \mathrm{s}$ (results not shown) because oxygen diffusion dominates convection and diffusion is most enhanced at the open edges. The upstream flame edge spread rate is nearly independent of the imposed flow velocity. This indicates sufficient oxygen supply to the edge flame and further increase in velocity will gradually cool the flame. The spread rate 
of the upstream edge flame is also influenced by heat losses to the sample holder, and by 3-D edge effects (diffusion of fuel vapor and heat conduction). The flame spread rate of the center part of the upstream flame increases with imposed wind velocity. Higher imposed velocity increases center flame temperature due to increased oxygen supply. Beyond a certain imposed wind velocity, the upstream edge flame and the center flame propagate at the same speed (as shown for the $5 \mathrm{~cm} / \mathrm{s}$ case).

Fig. 3 shows simulation results at 2, 4 and $6 \mathrm{~s}$ after the onset of external radiation for a wind velocity of $10 \mathrm{~cm} / \mathrm{s}$. For this case, we observe three flames as shown in Fig. 3c (a single upstream flame and two localized edge flames, one on either side of the plane of symmetry). The early stage of flame spread ( $\mathrm{t}=2 \mathrm{~s})$ shows a single flame propagating upstream (Fig. 3a), much like the case of $5 \mathrm{~cm} / \mathrm{s}$ (Fig. 2a). The fuel contours indicate increased supply of fuel from either side of the line of ignition, driven by heat feedback from the upstream flame. At $t=4 s$ (Fig. 3b), the oxygen isosurface indicate an oxygen shadow cast over the central part of the downstream flame. The central part of the downstream flame is therefore quenched. At the sample edges, fuel is burnt at a faster rate, because of lateral diffusion of oxygen. As the fuel is depleted, the edge flame exhibits a kink (Fig. 3b edge flame) where the flame approaches the sample surface. At some point the fuel source is completely depleted (fuel shaded contours in Fig. 3c) at the edge, no flame can be sustained in this region and we observe an edge flame propagating downstream independently of the upstream flame. Thus, the separation of the downstream edge flames from the upstream flame is due to the depletion of fuel. As compared to the $5 \mathrm{~cm} / \mathrm{s}$ case, the downstream edge flame for the $10 \mathrm{~cm} / \mathrm{s}$ case survives because of larger supply of oxygen. This is clearly observed by comparing the velocity vectors for the $5 \mathrm{~cm} / \mathrm{s}$ case (Fig. 2b) and $10 \mathrm{~cm} / \mathrm{s}$ case (Fig. 3b). Because the supply continues to increase with imposed flow velocity, the downstream edge flame spread rate also increases significantly with the flow velocity. We further observe that the downstream edge flame is weaker in intensity than the upstream flame and that the length of the flame at the center plane is longer than the edge flame. Since heat loss from the flame to the sample holder depends on the thermal properties and thickness of the holder material [5], the size and strength of the localized edge flames depends on the holder characteristics.

Fig. 4 shows simulation results at 2, 4 and $6 \mathrm{~s}$ after the imposition of external radiation for an imposed flow velocity of $20 \mathrm{~cm} / \mathrm{s}$. This case exhibits two separate flames, an intense flame 
propagating upstream and a weaker flame propagating downstream. The upstream flame is narrow, while the downstream flame is longer. Fig. 4a shows a single flame structure at $\mathrm{t}=2 \mathrm{~s}$ after ignition. This flame is much longer than the corresponding case for $10 \mathrm{~cm} / \mathrm{s}$. At t $=4 \mathrm{~s}$ (Fig. 4b), we observe the beginning of flame splitting which starts at the sample edges and gradually moves towards the center. The side view shows two separate flames at the sample edge and one flame at the center plane. The flame splitting initiates at the sample edge because the burning is most intense at the edge and this eventually depletes the fuel supply at the sample edges. For the $20 \mathrm{~cm} / \mathrm{s}$ case, we observe that at $\mathrm{t}=6 \mathrm{~s}$ the fuel supply is depleted along the entire width of the sample, resulting in a two-flame structure (See fuel shaded contours in Fig. 4b,c). The downstream edge flame is more intense than the center part of the flame and therefore spreads at a faster rate. It should be noted that the oxygen shadow cast by the upstream flame reduces in length as the imposed flow velocity increases. For the $5 \mathrm{~cm} / \mathrm{s}$ case, the shadow length is much longer, which results in quenching of the downstream flame. For the $20 \mathrm{~cm} / \mathrm{s}$ case, the oxygen shadow is limited to the regions occupied by the upstream flame as shown in Fig. 4c. This is the primary reason why the downstream flame is not quenched for the $20 \mathrm{~cm} / \mathrm{s}$ case. It is conceivable that a thermally thick sample would result in only one flame propagating upstream, with a long tail instead of the two flame structure for a thermally thin sample (because fuel depletion (burnout) does not occur).

Some of the numerically computed flame spread structures described above, are also observed in the drop tower experiments. Fig. 5 a, b and c (edge pictures of flame propagating for the case of $5 \mathrm{~cm} / \mathrm{s}$ in air) shows the downstream flame quenched shortly after the onset of ignition while the upstream flame continued to spread. This flame structure is very similar to the calculated results described in Fig. 2.

Fig. 5d (edge picture of flame propagating in air, for the case of $20 \mathrm{~cm} / \mathrm{s}$ ) shows a bright upstream flame with a long tail, shortly after ignition. However, after $4 \mathrm{~s}$, a kink appears in the middle part of the upstream flame (Fig. 5e). Finally, there are two separate flames, one bright flame spreading upstream and one weak (blue), long flame spreading downstream (Fig. 5f). This flame structure is very similar to the calculated results described in Fig. 4. Similar flame structures were observed in the drop tower experiments under $20 \mathrm{~cm} / \mathrm{s}$ in $35 \%$, oxygen but the contrast of the two flames (bright vs. weak blue) is more clear in the case of air. This is the reason why, pictures and results of flame propagation in air are used in this paper. The flame 
structure described in Fig. 1 has not been observed, because the smallest flow velocity used in this series of experiments was $2 \mathrm{~cm} / \mathrm{s}$ in $35 \%$ oxygen (one upstream flame was observed). Note that finger like flame structures propagating upstream, under low imposed velocity, close to the quenching limit (similar to the localized edge flames in Fig. 1) have been observed experimentally [10]. It is also difficult to confirm the flame structure described in Fig. 3, from the experiments conducted at $10 \mathrm{~cm} / \mathrm{s}$ in air and $35 \%$ oxygen, by examining the video images, due to limited test times of $10 \mathrm{~s}$ and the difficulty of distinguishing weak localized edge flames from the bright upstream flame. Further experimental study is planned to explore the confirmation of the flame structures described in Fig. 1 and 3.

For the $5 \mathrm{~cm} / \mathrm{s}$ imposed flow velocity, Fig. 6 shows the calculated and experimentally obtained positions of the leading edge (LE) and trailing edge (TE) of the flame as a function of time. The positions are relative to the center of the ignited area. The calculated results show that the upstream flame spread rate and the flame length stabilize about $2.0 \mathrm{~s}$ after ignition. Although a similar trend is observed in the experiments, the time to stabilize the trailing edge appears to be much longer (about $4 \mathrm{~s}$ ). Numerical simulations predict a leading edge flame spread rate of 3.6 $\mathrm{mm} / \mathrm{s}$ compared to the experimentally observed rate of $2.7 \mathrm{~mm} / \mathrm{s}$. Numerically computed trailing edge flame spread rate is $3.4 \mathrm{~mm} / \mathrm{s}$. In the experiments, the paper sample (char layer) is not perfectly level after the burning has occurred, and the downstream flame is influenced by this effect

Superimposed on Fig. 6 are leading edge and trailing edge positions for the upstream and downstream propagating flames for the $20 \mathrm{~cm} / \mathrm{s}$ case. Immediately after ignition, we observe a single flame propagating upstream in both numerically calculated results and experimental data. The location of the trailing edge of upstream flame indicates that the flame length is increasing with time. Numerical results and experimental data both indicate the position of the new downstream propagating flame, formed because of fuel depletion of the thermally thin sample (Fig. 6). As the fuel supply is depleted the flame approaches the sample surface. This is visible in edge views (Fig. $4 \mathrm{~b}$ and 5e) where a kink in the flame is beginning to form. A stage is reached when the entire fuel supply has been depleted at a point on the center plane. Two flame structures are observed beyond this point. We predict a spread rate of $-3.6 \mathrm{~mm} / \mathrm{s}$ and $-5.2 \mathrm{~mm} / \mathrm{s}$ for the LE and TE respectively. The length of the downstream flame (shown to increase with time) is much longer than the upstream flame. Experimentally, the downstream flame is so long 
that its trailing edge extended beyond the observation window. Overall, both numerical and experimental results indicate similar trends for flame break up and propagation of a two flame structure for the $20 \mathrm{~cm} / \mathrm{s}$ case.

\section{Conclusions}

The three-dimensional model predicts many different flame structures during the transition from ignition to flame spread over a thermally thin cellulosic paper in zero gravity. The ignition is initiated across the sample width (generation of a line-shape flame) at the center part of the sample. At low imposed flow velocity, two localized, small flames are formed at the sample edges. As the imposed flow velocity is increased, a single flame propagating upstream is observed, followed by the formation of three flames (one upstream propagating flame and two small edge flames spreading downstream). Finally, two flames are formed, one spreading upstream and another downstream, simultaneously. Experimentally, the flame structure of an upstream spreading flame and two flames spreading in opposite direction simultaneously were observed from a limited number of tests in microgravity. The formation of these different flame structures is due to changes in lateral diffusive flux of oxygen from the outer flow to the flame, fuel depletion of the thermally thin sample, convective flow patterns and oxygen shadow caused by oxygen consumption at the upstream flame.

\section{Acknowledgements}

This work is supported by the NASA Microgravity Science Program under the InterAgency Agreement No. C-32090-K. The JAMIC experiments were funded by NASA and the New Energy and Industrial Technology Development Organization (NEDO) through the Japan Space Utilization Promotion Center. 


\section{REFERENCES}

1. Olson, S. L., Ferkul, P. V. and Tien, J. S., Proc. Combust. Inst. 22: 1213-1222 (1988).

2. Bhattacharjee, S., Altenkirch, R. A. and Sacksteder, K., Combust. Sci. Technol. 91:225-242 (1993).

3. McGrattan, K. B., Kashiwagi, T., Baum, H. R, and Olson, S. L., Combust. Flame 106:377391 (1996).

4. Altenkirch, R. A., Tang, L., Sacksteder, K., Bhattacharjee, S., and Delichatsios, M. A., Proc. Combust. Inst., 27:2515-2524 (1998).

5. Mell, W. E. and Kashiwagi, T., Proc. Combust. Inst., 28: 2785-2792 (2000).

6. Shih, Hsin-Yi and Tien, J.S., ibid. 2777-2784 (2000).

7. Mell, W. E, Olson, S. L. and Kashiwagi, T., Proc. Combust Inst., 28:2843-2849 (2000).

8. Kashiwagi, T., McGrattan, K.B., Olson, S.L., Fujita, O., Kikuchi, M. and Ito, K., Proc. Combust. Inst. 26: 1345-1352 (1996).

9. Nakamura, Y., Kashiwagi, T., Mcgrattan, K. B. and Baum, H. R., submitted, Comb. Flame, (2001).

10. Oravecz, L. M., Masters Thesis, Dept. of Mech. Engg., Michigan State University, May 2001. 


\section{LIST OF FIGURE CAPTIONS}

Fig. 1,2,3 and 4 (Composite Caption) Simulation results at various times after the onset of external radiation for an imposed wind velocity of $1.5 \mathrm{~cm} / \mathrm{s}$ (Fig.1), $5.0 \mathrm{~cm} / \mathrm{s}$ (Fig. 2), $10.0 \mathrm{~cm} / \mathrm{s}$ (Fig. 3) and $20.0 \mathrm{~cm} / \mathrm{s}$ (Fig. 4). Each figure shows tan colored isosurface of energy release rate value of $4000 \mathrm{Watt} / \mathrm{m}^{3}$ (gas phase reaction rate value of $0.114 \mathrm{~kg} / \mathrm{m}^{3} / \mathrm{s}$ ) and blue isosurface of oxygen mass fraction (0.05). The isosurfaces are restricted to $y>0$ and $y<0$ domain respectively. The sample edge, right and left clamp edge (solid lines) along with an overlaid grid (dotted line) has also been shown. Energy release rate shaded contours (2000 to 20,000 Watt/ $\mathrm{m}^{3}$ ) on slice plane located at $\mathrm{y}=0$ and $\mathrm{y}=3.75 \mathrm{~cm}$ have been projected on planes located at $\mathrm{y}=-6 \mathrm{~cm}$ and $\mathrm{y}=6$ $\mathrm{cm}$ respectively. These slice planes show the side view of the flame at the center plane and the sample edge plane. Energy release rate contours (shaded) on the $\mathrm{z}=3.6 \mathrm{~mm}$ plane and fuel mass fraction contours (line) on the $\mathrm{z}=0.6 \mathrm{~mm}$ plane (first grid cell above the sample) are also shown. The energy release rate contours (shaded) are in the $y>0$ domain, provide a top view of the flame shape at the $\mathrm{z}=3.6 \mathrm{~mm}$ plane. The fuel mass fraction contours (line) are restricted to the $\mathrm{y}<0$ domain. The surface translucency of the isosurfaces is set to a very high number $(80 \%)$ in order to visualize the inner details of the flame structure. Net oxygen mass flux vectors on the $\mathrm{z}=3.6$ $\mathrm{mm}$ plane (convective and diffusive component) are shown in the $\mathrm{y}>0$ domain. The convective component alone is shown in the $\mathrm{y}<0$ domain. These vectors are color coded with oxygen mass fraction. The length of these vectors is proportion to the flux. Since the mesh is extremely refined, every sixth vector is plotted in the $\mathrm{x}$ and $\mathrm{y}$ direction for clarity.

-Page 15

Fig. 5 Color images of the edge view for flame spread in microgravity conditions obtained from the drop tower experiments. Figures 5 . a, b and c are for an imposed flow velocity of $5 \mathrm{~cm} / \mathrm{s}$ at $\mathrm{t}=2 \mathrm{~s}(\mathrm{a}), 6.5 \mathrm{~s}$ (b) and $9.5 \mathrm{~s}$ (c) from the onset of external radiation. Figures 5. d, e and f are for an imposed flow velocity of $20 \mathrm{~cm} / \mathrm{s}$ at $\mathrm{t}=4 \mathrm{~s}$ (a), $8 \mathrm{~s}$ (b) and $9.5 \mathrm{~s}$ (c) from the onset of external radiation. The flow is from right to left and the flames are propagating in air.

Page 16

Fig. 6 Comparison of numerical and experimental results for flame position as a function of time. Each figure shows the location of the leading edge and trailing edge of the upstream propagating flame as a function of time for an imposed wind speed of $5.0 \mathrm{~cm} / \mathrm{s}$. The corresponding locations for the upstream and downstream propagating flames for an imposed 
wind speed of $20.0 \mathrm{~cm} / \mathrm{s}$ have also been shown. The calculated locations are plotted for flames at the center plane where the reaction rate value is $1000 \mathrm{Watt} / \mathrm{m}^{3}$ (Reaction rate $=0.01 \mathrm{~kg} / \mathrm{m}^{3} / \mathrm{s}$ ) and are relative to the location of the incident radiant flux. The experimentally determined locations are obtained from the edge view pictures some of which are shown in Fig. 5.

-Page 17 

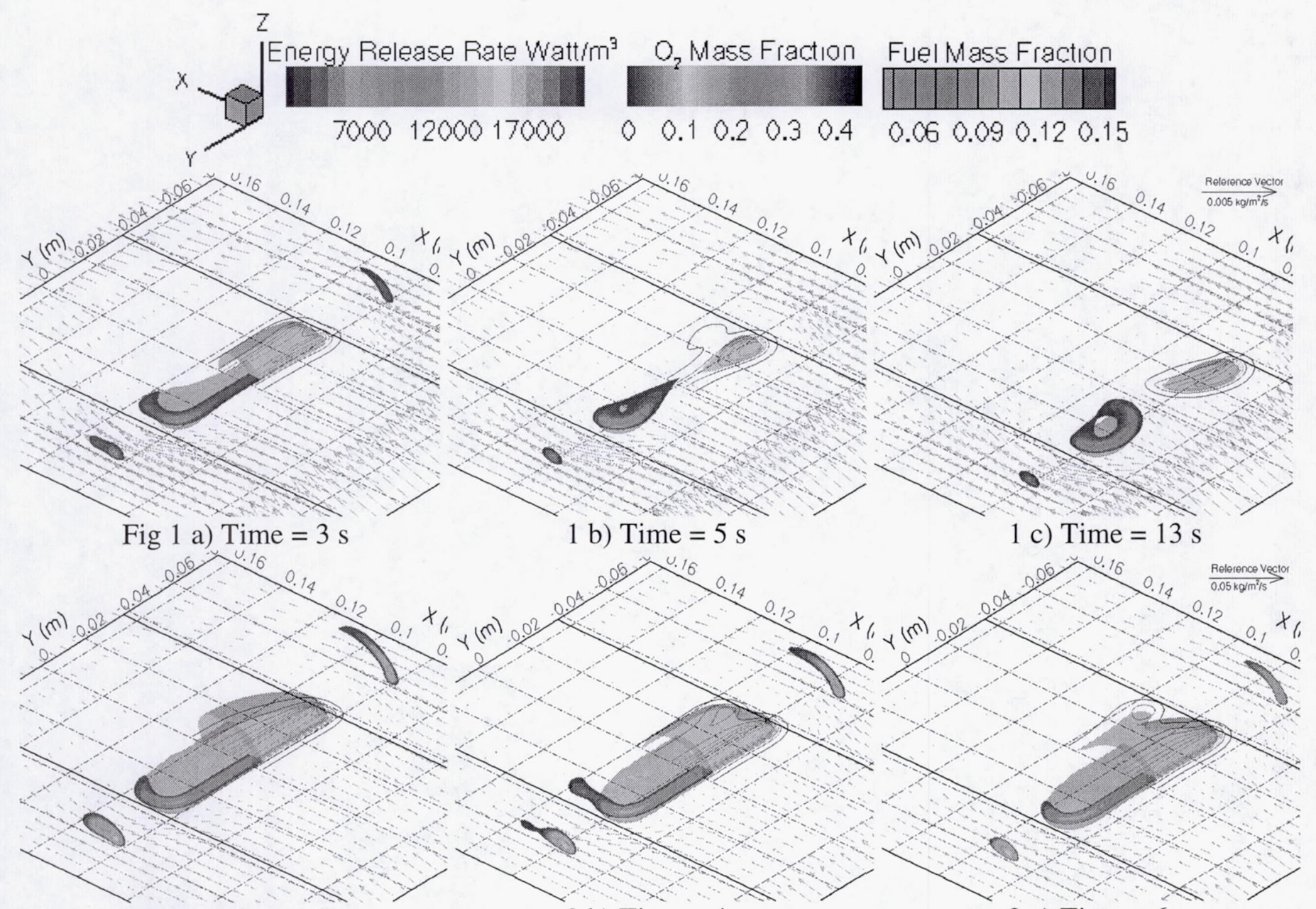

$1 \mathrm{~b})$ Time $=5 \mathrm{~s}$

1 c) Time $=13 \mathrm{~s}$

Fig 2 a) Time $=2 \mathrm{~s}$

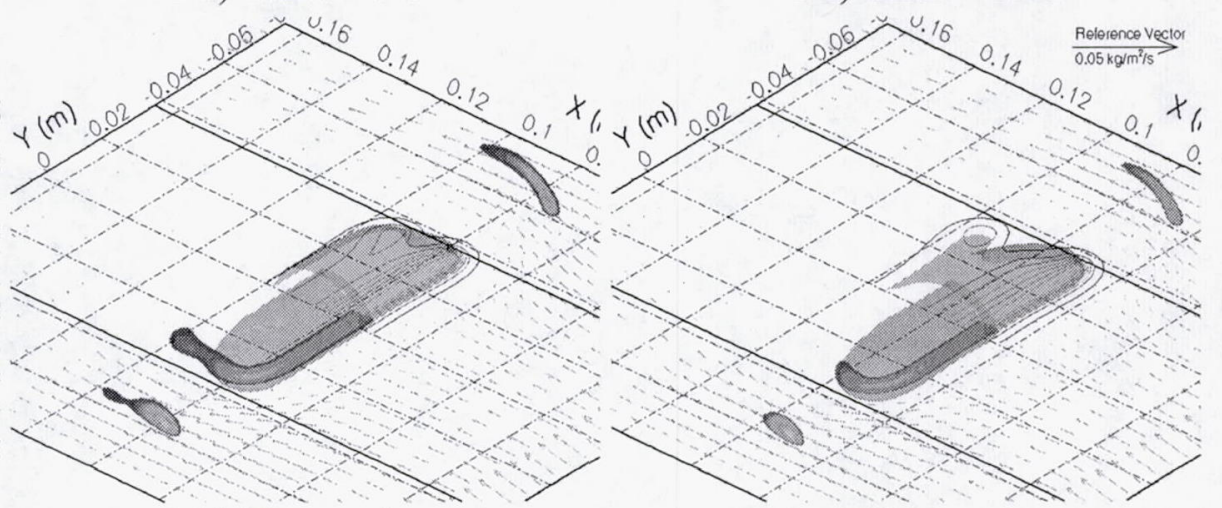

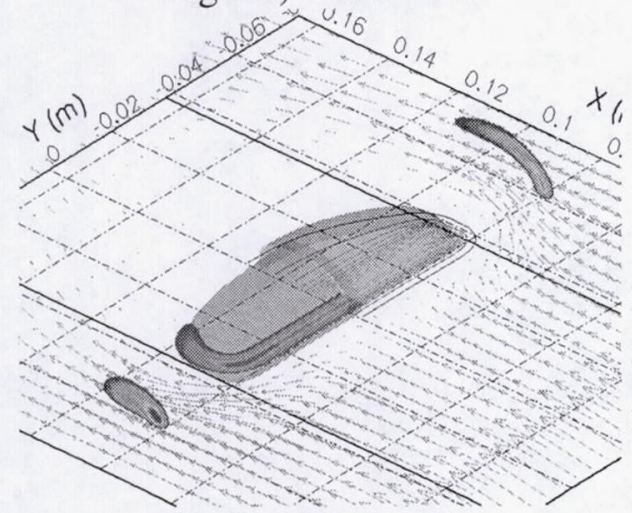

Fig 3 a) Time $=2 \mathrm{~s}$
$2 \mathrm{~b})$ Time $=4 \mathrm{~s}$

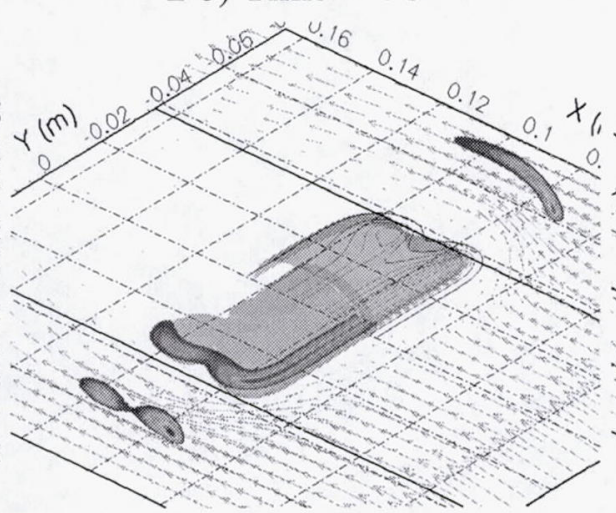

$3 \mathrm{~b})$ Time $=4 \mathrm{~s}$

2c) Time $=6 \mathrm{~s}$

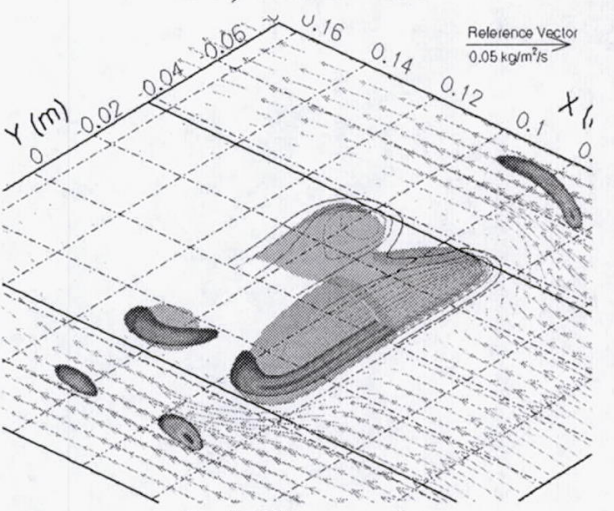

3c) Time $=6 \mathrm{~s}$

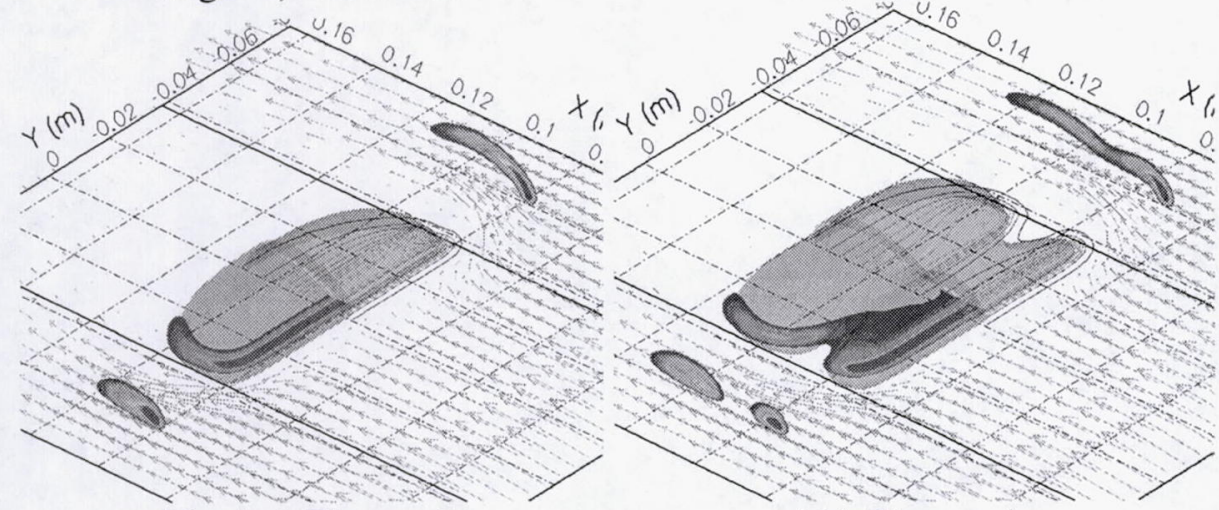

Fig 4 a) Time $=2 \mathrm{~s}$

4 b) Time $=4 \mathrm{~s}$

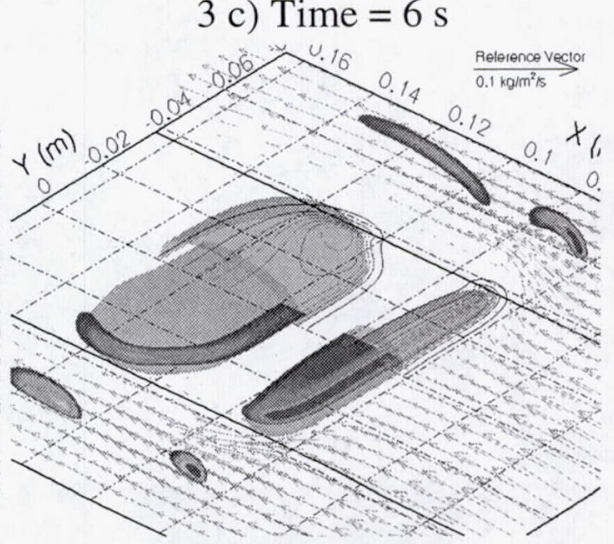

$4 \mathrm{c})$ Time $=6 \mathrm{~s}$ 


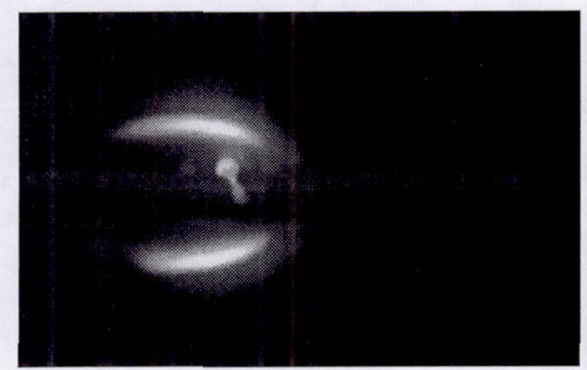

(a)

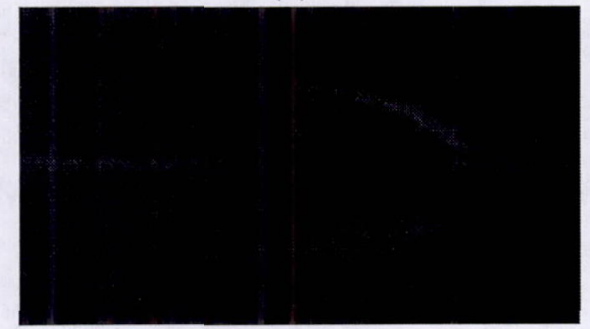

(b)

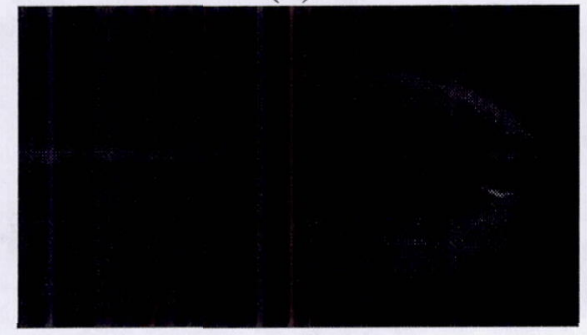

(c)

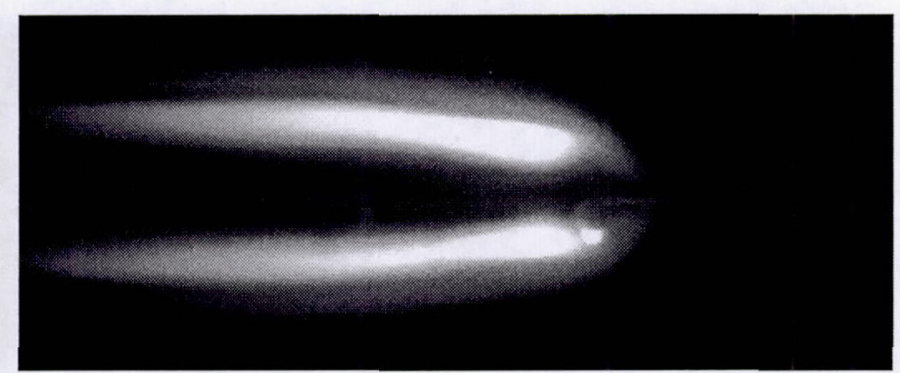

(d)

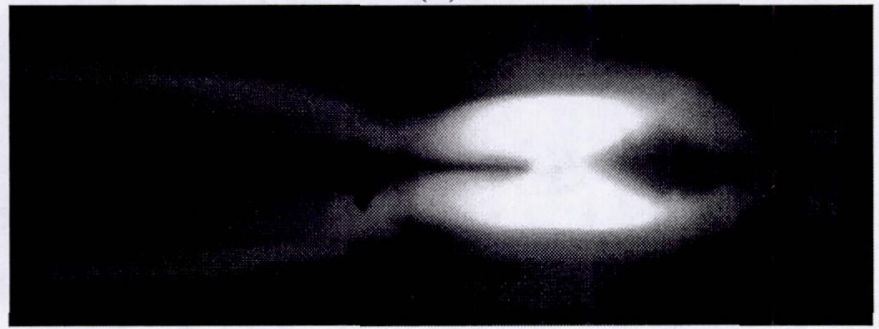

(e)

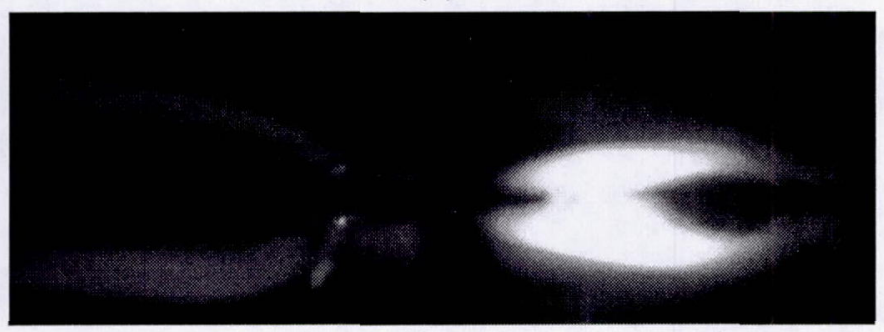

(f)

Fig. 5 Color images of the edge view for flame spread in microgravity conditions obtained from the drop tower experiments. Figures 5. a, b and c are for an imposed flow velocity of $5 \mathrm{~cm} / \mathrm{s}$ at t=2 s (a), $6.5 \mathrm{~s}$ (b) and $9.5 \mathrm{~s}$ (c) from the onset of external radiation. Figures 5. d, e and $\mathrm{f}$ are for an imposed flow velocity of $20 \mathrm{~cm} / \mathrm{s}$ at $\mathrm{t}=4 \mathrm{~s}$ (a), $8 \mathrm{~s} \mathrm{(b)} \mathrm{and} 9.5 \mathrm{~s}$ (c) from the onset of external radiation. The flow is from right to left and the flames are propagating in air. 


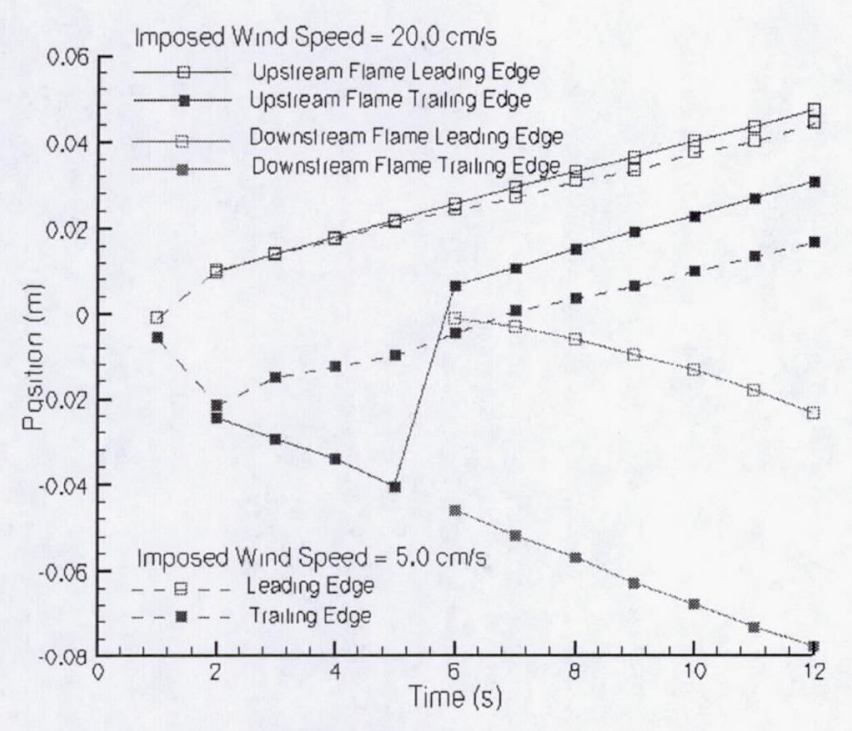

a) Numerical Results

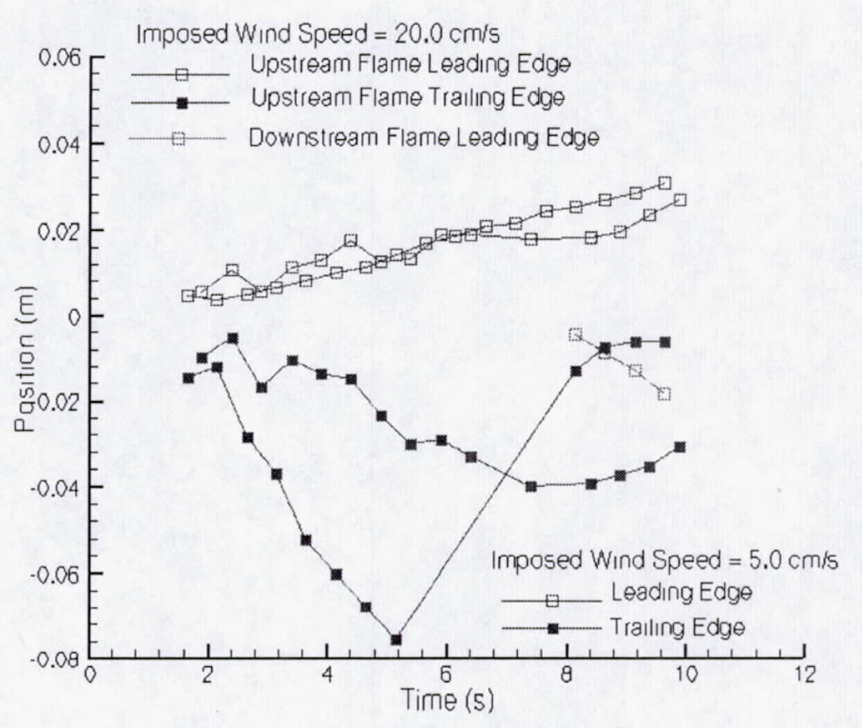

b) Experimental Results

Fig. 6 Comparison of numerical and experimental results for flame position as a function of time. Each figure shows the location of the leading edge and trailing edge of the upstream propagating flame as a function of time for an imposed wind speed of $5.0 \mathrm{~cm} / \mathrm{s}$. The corresponding locations for the upstream and downstream propagating flames for an imposed wind speed of $20.0 \mathrm{~cm} / \mathrm{s}$ have also been shown. The calculated locations are plotted for flames at the center plane where the reaction rate value is $1000 \mathrm{Watt} / \mathrm{m}^{3}$ (Reaction rate $=0.01 \mathrm{~kg} / \mathrm{m}^{3} / \mathrm{s}$ ) and are relative to the location of the incident radiant flux. The experimentally determined locations are obtained from the edge view pictures some of which are shown in Fig. 5. 